\title{
Treatment of Recurrent Hepatocellular Carcinoma with Sorafenib in a HIV/HCV Co-Infected patient in HAART: A Case Report
}

\author{
Pasquale De Nardo ${ }^{*}$, Magdalena Viscione ${ }^{1}$, Angela Corpolongo ${ }^{1}$, Rita Bellagamba', Giovanni Vennarecci², \\ Giuseppe Maria Ettorre ${ }^{2}$, Elisa Gentilotti ${ }^{1}$, Chiara Tommasi ${ }^{1}$ and Emanuele Nicastri ${ }^{1}$
}

\begin{abstract}
Background: Liver disease is the second cause of death among HIV patients receiving highly active antiretroviral therapy (HAART) in Europe. HIV patients have a high prevalence of chronic HBV (6-10\%) and HCV (33\%) co-infection , and accelerated progression of viral hepatitis. Furthermore, the long duration of both HIV and HCV diseases in the HAART era increases the risk of hepatocellular carcinoma.

Findings: We report the case of a 49 year -old HIV/HCV co-infected male patient who developed hepatocellular carcinoma. The patient underwent a partial hepatectomy, and a few months later was treated with transcatheter arterial chemoembolisation due to hepatocarcinoma recurrence. Two months later, advanced hepatocellular carcinoma was diagnosed and sorafenib therapy was initiated. The patient achieved partial response of the main lesions, complete regression of the smallest lesions and did not experience clinical progression during the 20month follow-up period. During therapy with sorafenib, the patient was treated with HAART with good viral and immunological responses. We used the therapeutic drug monitoring to assess antiretroviral concentrations during co-administration of sorafenib. Fosamprenavir $C_{\text {trough }}$ was found under the minimum level recommended by international guidelines. No grade 3 or 4 toxicities were observed. At month 20 of treatment, new liver lesions with portal vein thrombosis were diagnosed. After 28 months of sorafenib therapy, the patient deceased for severe liver insufficiency.
\end{abstract}

Conclusions: Sorafenib monotherapy demonstrated a marked delay in HCC disease progression in an HIV/HCV coinfected patient. Fosamprenavir $C_{\text {trough }}$ was found under the minimum level recommended by international guidelines, suggesting a possible interaction.

Keywords: HAART, Sorafenib, Fosamprenavir, TDM, Hepatocarcinoma, HIV/HCV co-infection

\section{Findings} Introduction

People infected with HIV have a greater prevalence of chronic HBV (6-10\%) and HCV (33\%) and accelerated progression of viral hepatitis than the general population [1]. Since the initiation of highly active antiretroviral therapy (HAART) in 1996, the incidence of AIDS-related morbidity and mortality has dramatically decreased, resulting in increased life expectancy. However, the causes of death have shifted from AIDS-defining to non -AIDS defining diseases

\footnotetext{
* Correspondence: pasqualedenardo@libero.it

${ }^{1}$ Clinical Department of Infectious Diseases, National Institute for Infectious Diseases IRCCS "L. Spallanzani", via Portuense 292, 00149, Rome, Italy Full list of author information is available at the end of the article
}

with increased risk of end-stage liver diseases (ESLD) [2]. According to several studies, the complications of HCV and HBV are the second most frequent cause of death after AIDS in HIV- infected patients, accounting for around 10\% of deaths $[2,3]$. Two large, phase III trials demonstrated that the orally active multikinase inhibitor sorafenib is effective in leading to a longer median overall survival time, and time to progression in patients with advanced hepatocellular carcinoma (HCC) $[4,5]$. Despite the clinical relevance of HCC in HIV-HCV co-infection, there is little data regarding the use of sorafenib for HCC in HIV/HCV co-infected patients. Furthermore, data on a possible interaction between sorafenib and antiretrovirals are rather scarce [6-8].

\section{Biomed Central}




\section{Case report}

A 49 year-old Italian male with HIV infection (known since 1988), and CDC stage C3 for pulmonary tuberculosis, presented an $\mathrm{HCV}$ infection (genotype 4) since 1992. His HBV-DNA and hepatitis B surface antigens were negative. He was on antiretroviral therapy since 1991 with good immune-virological control. In December 2005, a liver biopsy showed a moderate grade of necroinflammatory activity and a moderate intensity of fibrosis (Ishak grading 13, Ishak staging 3). HAART was interrupted in March 2006, and in May 2006, he started antiviral treatment with Peg-interferon $180 \mathrm{mcg} /$ week and ribavirin $1000 \mathrm{mg} /$ day. Sixteen weeks later, antiviral therapy was discontinued for virological failure (> 300.000 HCV-RNA UI/mL). In June 2007, 15 months after HAART interruption, the patient started another antiretroviral therapy with emtricitabine (FTC), tenofovir (TDF), fosemprenavir (FPV) and ritonavir (RTV) (100 $\mathrm{mg}$ daily): the $\mathrm{C}_{\text {trough }}$ determination of FPV was $1176 \mathrm{ng} / \mathrm{mL}$, far above the $\mathrm{C}_{\text {trough }}$ levels suggested by international guidelines ( $>400 \mathrm{ng} / \mathrm{mL}$ ) [9]. In July 2007, an abdomen computed tomography scan (TC) showed a single nodule of $4 \mathrm{~cm}$ in the VI hepatic segment. A histological diagnosis of $\mathrm{HCC}$ was made and he underwent a partial hepatectomy. In April 2008, a new liver lesion of $2.4 \mathrm{~cm}$ in the VII-VIII segment was detected and treated with Transcatheter Arterial Chemoembolisation (TACE). Three months later, an abdomen $\mathrm{CT}$ scan revealed a right subdiaphragmatic fluid collection and a nonhomogenic solid nodular lesion on the resection margin of the previous hepatectomy (Figure 1). Smaller lesions were described in II, III and IV segments. His $\alpha$ fetoprotein was $20.43 \mathrm{IU} / \mathrm{ml}$. In December 2008, the patient started treatment with sorafenib $800 \mathrm{mg} / \mathrm{die}$, which was reduced to $400 \mathrm{mg} /$ day after 2 months due to a grade II hand-foot skin adverse reaction. Child-Pugh

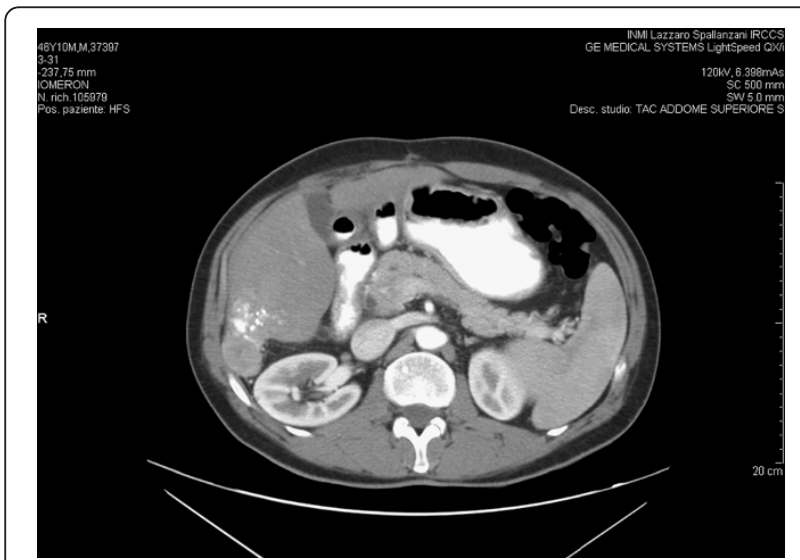

Figure 1 Abdomen TC scan before starting sorafenib. Nonhomogenic solid nodular lesion on the resection margin of the hepatectomy. cirrhosis score at the beginning of sorafenib treatment was 6 , grade A. The radiological controls during followup, until month 20 of therapy showed complete regression of the described nodular lesion with no progression of the smaller lesions (Figure 2). No appearance of new relapses was observed. Fosamprenavir $\mathrm{C}_{\text {trough }}$ was found under the minimum level recommended by international guidelines $\left(C_{\text {trough: }} 115 \mathrm{ng} / \mathrm{mL}\right.$; $C$ max: $\left.436 \mathrm{ng} / \mathrm{mL}\right)$. Nevertheless, HIV-RNA was still undetectable. At month 20 of treatment, we found an increment of $\alpha$-fetoprotein up to $200 \mathrm{IU} / \mathrm{ml}$, associated with new hepatic lesions and occurrence of a complete portal vein thrombosis. Sorafenib administration continued after the documented disease progression. In April 2011, after 28 months of sorafenib therapy, the patient deceased for severe liver insufficiency. A summary of CD4 cell count and HIVRNA values is showed in Table 1 . Over the entire period of treatment with sorafenib the patient had taken PIbased HAART, which was well-tolerated, and had maintained a good viral immunological response (CD4 > 500/ $\mathrm{mmc}$ and undetectable viremia), despite low levels of fosamprenavir concentration. The more severe toxicities correlated to sorafenib assumption were grade II handfoot skin reaction which required a dose reduction.

\section{Discussion}

HCC is the fifth most common cancer in the world and the third most common cause of cancer death. The main risk factors for developing HCC are the presence of cirrhosis and co-infection with HBV and HCV [10].

HIV co-infection worsens the course of viral hepatitis causing faster progression of fibrosis and earlier development of cirrhosis. On the other hand, the introduction of HAART has increased longevity. Consequently, the

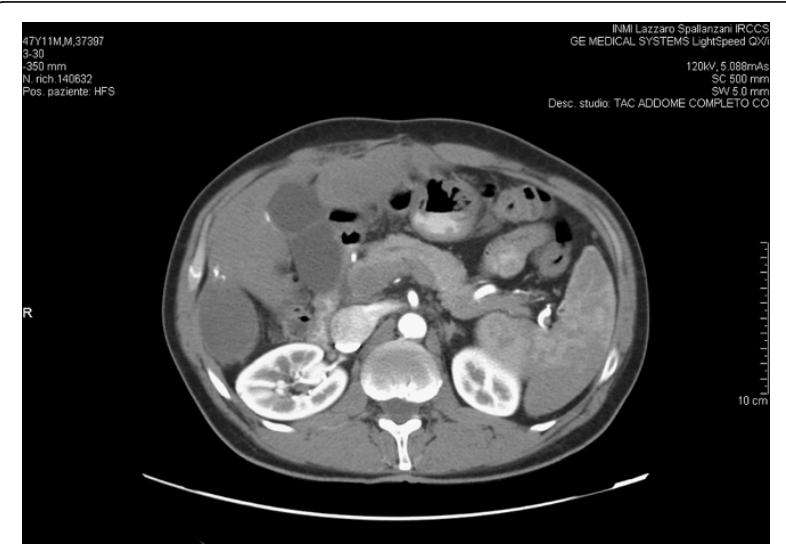

Figure 2 Abdomen TC scan: follow up during sorafenib treatment. Right subdiaphragmatic fluid collection with no appearance of the solid nodular lesion (same anatomic level of Figure 1). 
Table 1 Summary of CD4 cell count and HIV-RNA values

\begin{tabular}{llll}
\hline & CD4 cell/mmc (\%) & HIV-RNA (cp/mL) & Notes \\
\hline Mar 2006; May 2006 & $574(15.5)$ & $<50$ & Stop HAART; Start Peg-IFN + RIBA \\
Sep 2006 & $357(18.8)$ & 12596 & Stop Peg-IFN + RIBA \\
Oct 2006- Sep 2007 & $>350$ & $\geq 30000 \leq 50000$ & HCC diagnosis and hepatectomy \\
Jun 2007 & $277(13.2)$ & 85462 & Restart HAART \\
Jan 2008 & $506(21.1)$ & $<50$ & HCC relapse \\
Apr 2008 & $384(23.6)$ & $<50$ & Start sorafenib \\
Dec 2008 & $526(23.7)$ & $<50$ & \\
\hline
\end{tabular}

HAART: highly active antiretroviral treatment; Peg-IFN: pegylated- interferon; RIBA: ribavirin; HCC: hepatocarcinoma.

manifestations of end-stage liver disease, particularly $\mathrm{HCC}$, are more frequently reported [11].

According to current guidelines, treatment of $\mathrm{HCC}$ is the same for both patients with and without HIV infection, although the outcome is worse for HIV-positive patients than their HIV-negative counterparts [11]. Until 2007, chemotherapy had not shown survival benefits for these patients because the HCC is generally a chemoresistant tumor [12]. Sorafenib, a new biological drug recently approved in the EU and USA, has substantially changed the treatment and natural course of advanced unresectable HCC. The introduction of this drug has offered a therapeutic opportunity to patients for whom no effective treatment was previously available. Sorafenib is a tyrosine kinase inhibitor directed against several targets (including vascular-endothelial growth factor VEGFR2, platelet-derived growth factor (PDGFR)-b and Raf kinase) that has demonstrated the ability to inhibit tumor proliferation and angiogenesis in vitro. Two randomized, double-blind, placebo-controlled, multicentre, phase III trials (the SHARP trial and the Asia-Pacific trial) have proved that monotherapy with oral sorafenib prolonged median overall survival and delayed the median time to progression in patients with advanced HCC [13].

Three cases of HIV-positive patients treated with sorafenib have been described in literature: two patients coinfected with HBV $[6,8]$ and one patient co-infected with HCV [7]. Our case is the second report describing the use of sorafenib for HCC in an HIV-HCV co-infected patient. Our patient's survival after administration of sorafenib was remarkably prolonged compared with the overall median survival observed in two recent placebocontrolled trials (20 months vs. 10,7 months [4] and 6,5 [5]), with no grade 3-4 toxicity. Since objective responses for $\mathrm{HCC}$ patients treated with sorafenib are very rare, this fuels the hypothesis of a possible synergistic effect of sorafenib with HAART. In particular, ritonavir, a protease inhibitor, can inhibit both in vivo and in vitro the $\mathrm{PI} / \mathrm{AKT} / \mathrm{mTOR}$ pathway and that could provide a molecular biology rationale for explaining, at least in part, the observed objective response. As previously described [7], a 50\% dose reduction of sorafenib to $200 \mathrm{mg}$ twice daily was scheduled for safety reasons. Metabolism of sorafenib occurs primarily in the liver, mediated via cytochrome P450 (CYP) 3A4, and concomitant administration with CYP3A4 inducers or inhibitors may modify sorafenib concentrations [13]. Emtricitabine and tenofovir have no interactions with P450 (CYP) 3A4 enzyme , but fosemprenavir (FPV) and ritonavir (RTV) are both P450 CYP3A4 inhibitors and since sorafenib is metabolized through P450 CYP3A4 that could result in an increase of the active dose of sorafenib explaining the favorable outcome for the patient. Consistent with the limited literature data, a good immune-virological response to HAART was maintained throughout the sorafenib therapy, despite low levels of fosamprenavir concentration. Different from the other two cases, at month 20 of treatment with sorafenib, our patient showed an increase in alpha-fetoprotein values. The occurrence of portal vein thrombosis and new lesions clearly identify HCC disease progression.

In conclusion, sorafenib may represent a good therapeutic option also for the treatment of HIV-HCV coinfected patients with advanced HCC who are not candidates for surgery or palliative care. However, longitudinal clinical trials are required in order to confirm both efficacy and safety of sorafenib in co-administration with antiretroviral drugs.

Competing interests

None; no financial support was received.

\section{Authors' contributions}

All authors contributed to the manuscript. PDN was involved in drafting the manuscript and reviewing the literature. AC, MV and RB were responsible for the primary management of the patient. CT and EG helped to draft the manuscript. GV and GME provided the figures and helped to draft the manuscript. EN revised the final manuscript and has given the final approval of the version to be published. All authors have read and approved the final manuscript. 


\section{Acknowledgements}

The authors acknowledge all contributors to this manuscript.

\section{Author details}

${ }^{1}$ Clinical Department of Infectious Diseases, National Institute for Infectious Diseases IRCCS "L. Spallanzani", via Portuense 292, 00149, Rome, Italy.

${ }^{2}$ General and Transplant Surgery, San Camillo-Forlanini Hospital, via Portuense 292, 00149, Rome, Italy.

Received: 18 April 2012 Accepted: 22 June 2012

Published: 28 June 2012

\section{References}

1. Sulkowski M: Hepatocellular carcinoma in HIV-infected patients comes of age: the convergence of epidemiology and treatment effectiveness. J Hepatol 2009, 50:655-658.

2. Weber R, Sabin CA, Friis-Møller N, Reiss P, El-Sadr WM, Kirk O, Dabis F, Law MG, Pradier C, De Wit S, Akerlund B, Calvo G, Monforte A, Rickenbach M, Ledergerber B, Phillips AN, Lundgren JD: Liver related deaths in persons infected with the human immunodeficiency virus: the D:A:D study. Arch Intern Med 2006, 166:1632-1641.

3. Giordano TP, Kramer JR, Souchek J, Richardson P, El-Serag HB: Cirrhosis and hepatocellular carcinoma in HIV infected veterans with and without the hepatits C virus: A cohort study, 1992-2001. Arch Intern Med 2004, 164:2349-2354.

4. Llovet JM, Ricci S, Mazzaferro V, Hilgard P, Gane E, Blanc JF, de Oliveira AC, Santoro A, Raoul JL, Forner A, Schwartz M, Porta C, Zeuzem S, Bolondi L, Greten TF, Galle PR, Seitz JF, Borbath I, Häussinger D, Giannaris T, Shan M, Moscovici M, Voliotis D, Bruix J, SHARP Investigators Study Group: Sorafenib in advanced hepatocellular carcinoma. N Engl J Med 2008, 359:378-390.

5. Cheng AL, Kang YK, Chen Z, Tsao CJ, Qin S, Kim JS, Luo R, Feng J, Ye S, Yang TS, Xu J, Sun Y, Liang H, Liu J, Wang J, Tak WY, Pan H, Burock K, Zou J, Voliotis D, Guan Z: Efficacy and safety of sorafenib in patients in the AsiaPacific region with advanced hepatocellular carcinoma: A phase III randomized, double-blind, placebo-controlled trial. Lancet Oncol 2009, 10:25-34.

6. Chelis L, Ntinos N, Souftas V, Deftereos S, Xenidis N, Chamalidou E, Maltezos E, Kakolyris S: Complete response after sorafenib therapy for hepatocellular carcinoma in an HIV-HBV co- infected patient: Possible synergy with HAART ? A case report. Med Oncol 2011, 28:S165-S168.

7. Perboni G, Costa P, Fibbia GC, Morandini B, Scalzini A, Tagliani A, Cengarle R, Aitini E: Sorafenib Therapy for Hepatocellular Carcinoma in an HIV-HCV co-infected Patient: A Case Report. Oncologist 2010, 15:142-145.

8. Ozenne V, Gervais A, Peytavin G, Castelnau C, Valla DC, Degos F: Suspected interaction between sorafenib and HAART in an HIV-1 infected patient: a case report. Hepatogastroenterology 2011, 58(105):161-162.

9. Panel on Antiretroviral Guidelines for Adults and Adolescents. Guidelines for the use of antiretroviral agents in HIV-1-infected adults and adolescents., : [http://www.aidsinfo.nih.gov].

10. Sherman M: Hepatocellular Carcinoma: Epidemiology, Surveillance, and Diagnosis. Semin Liver Dis 2010, 30:3-16.

11. Macdonald DC, Nelson M, Bower M, Powles T: Hepatocellular carcinoma, human immunodeficiency virus and viral hepatitis in the HAART era. World J Gastroenterol 2008, 14(11):1657-1663.

12. Gish $R G$, Marrero JA, Benson AB: A multidisciplinary approach to the management of hepatocellular carcinoma. Gastroenterol Hepatol (N Y) 2010, 6(3 Suppl 6):1-16.

13. Keating GM, Santoro A: Sorafenib: a review of its use in advanced hepatocellular carcinoma. Drugs 2009, 69(2):223-240.

\section{Submit your next manuscript to BioMed Central and take full advantage of:}

- Convenient online submission

- Thorough peer review

- No space constraints or color figure charges

- Immediate publication on acceptance

- Inclusion in PubMed, CAS, Scopus and Google Scholar

- Research which is freely available for redistribution

Submit your manuscript at www.biomedcentral.com/submit 